Article

\title{
Modelling Hydration Swelling and Weakening of Montmorillonite Particles in Mudstone
}

\author{
Changlun Sun ${ }^{1,2}$, Guichen $\mathrm{Li}^{1,2, *(0)}$, Yuantian Sun ${ }^{1,2}$, Jintao He ${ }^{1,2}$ and Haoyu Rong ${ }^{1,2}$ \\ 1 Key Laboratory of Deep Coal Resource Mining, Ministry of Education of China, China University of Mining \\ and Technology, Xuzhou 221116, China \\ 2 School of Mines, China University of Mining and Technology, Xuzhou 221116, China \\ * Correspondence: Liguichen@126.com; Tel.: +86-158-0521-5566
}

Received: 18 May 2019; Accepted: 3 July 2019; Published: 5 July 2019

check for updates

\begin{abstract}
It is of paramount importance to understand the hydration swelling and weakening properties of clay minerals, such as montmorillonite, to determine their mechanical responses during deep underground argillaceous engineering. In this study, the mineral components and microscopic structure of mudstone were characterised using X-ray powder diffraction and field-emission scanning electron microscopy. Experimental schemes were devised to determine the properties of mudstone under the influence of underground water and stress; these involved compacting montmorillonite particles with various water contents and conducting uniaxial compression tests. Experimental results demonstrated that compaction stress changes the microscopic structure of the montmorillonite matrix and affects its properties, and stress independency was found at particular water and stress conditions. Two equations were then obtained to describe the swelling and weakening properties of the montmorillonite matrix based on the discrete element method; further, the hydration swelling equation represents the linear decrease in the density of the montmorillonite matrix with an increase in the water content. It was also determined that the water dependency of uniaxial compressive strength can be described by negative quartic equations, and the uniaxial compressive strength of the montmorillonite matrix is just $0.04 \mathrm{MPa}$ with a water content of 0.6. The experimental results are in good agreement with the calculated solutions and provide an important experimental basis to the understanding of the mechanical properties of montmorillonite-rich mudstones under the influence of underground water and stress.
\end{abstract}

Keywords: mudstone; montmorillonite; particle; hydration; swelling and weakening

\section{Introduction}

Advances made to understand the behaviour of mudstone over the last 50 years have shown the importance of the role of clay mineral components when modelling its behaviour. In the field of geotechnical and hydraulic engineering, soil and rock comprised of montmorillonite have an adverse effect on the stability of engineering structures owing to the layered molecular structure of montmorillonite and its hydration swelling and weakening properties [1-3].

Conventional experiments conducted to investigate the influence of water on the physical and mechanical properties of mudstone have often used natural mudstone as the research objective. Such experiments have investigated the reaction between water and mudstone through methods involving immersion, drying and moisture absorption. In the process of water saturation, the compressive, tensile and shear strength of mudstone decrease exponentially with the increase of length of time that it is immersed in water [4], whereas the shear modulus increases and the mudstone strengthens during the drying process at different temperatures [5]. Experiments on water-rock interactions have been conducted under different environmental humidity conditions, and it has been 
determined that when the moisture content is lower, the air permeability is improved [6] and the strain rate is lower in the creep process [7]. In addition, under conditions of constant humidity, a mudstone indentation test showed that with an increase in relative humidity, the elastic modulus and strength of mudstone decreases and plastic deformation increases [8]. However, the abovementioned studies have not considered the influence of clay mineral components on the reaction between water and mudstone. Mudstone is a type of heterogeneous material made of fine clays in a matrix with larger detrital minerals embedded between the clay particles $[9,10]$; therefore, the physical and mechanical properties of mudstone vary with the clay mineral content. Armand et al. studied the mechanical behaviour of callovo-oxfordian claystone and found that mudstone with a higher clay mineral content has a lower strength [11]. It has also been determined that as the content of montmorillonite increases, the friction coefficient of the gouge decreases $[12,13]$. Tembe and Lockner found that the friction coefficient decreased from 0.75 to 0.30 as the illite content increased in a mixture of illite and quartz [14]. Results have shown that clay mineral types have a significant impact on the weakening characteristics of mudstone under the influence of water [15-17]: montmorillonite has a strong interaction with water, illite has a medium interaction and kaolinite has high water stability. Therefore, to quantify the intensity of the reaction between mudstone and water, the hydration characteristics of clay minerals, or the key clay minerals in mudstone, need to be quantified first. In this respect, the hydration swelling and weakening law is of particular significance because hydration expansion produces internal stress and destroys the entire structure of mudstone, while hydration weakening reduces the stability of mudstone under the influence of an external force.

Compacted tests have been widely used to investigate the physical and mechanical characteristics of clay minerals in geotechnical and hydraulic engineering fields. Mukherjee and Mishra researched the hydraulic and mechanical characteristics of compacted sand-bentonite, including hydraulic conductivity and shear strength [18]. Villar and Antonio prepared samples by means of the uniaxial compaction of clay directly in oedometer rings to analyze the swelling of a compacted bentonite [19]. Additionally, $\mathrm{Xu}$ and $\mathrm{Li}$ et al. compacted mixed soil with a bentonite in three layers to research the deformation and hydraulic conductivity of compacted clay [20]. To investigate the unconfined compressive strength of clay mixture, Nilo and Eduardo et al. adopted static compaction to model and cure specimens [21]. In [22], Kumar and Walia et al. compacted the soil in the mould with a mixture of sand and conducted compressive strength tests to research the effect of mixing sand on the mechanical properties of clay. The clay minerals of mudstone can also be investigated by a similar experimental method.

The main aim of this paper is to research the swelling and disintegration processes of mudstone. Therefore, the mineral components and microscopic structure of mudstone obtained from the Donghuantuo Mining Company were firstly characterised using X-ray powder diffraction (XRD) and field-emission scanning electron microscopy (FE-SEM) to investigate the clay matrix within mudstone and associated influential factors. Experimental schemes were then designed to research the hydration swelling and weakening of the montmorillonite matrix therein. Two equations-one that describes swelling and one that describes weakening - were then derived based on the discrete element method. Finally, the experimental results were compared with those calculated using the swelling and weakening models.

\section{Characterisation of Mudstone}

\subsection{Sample Collection}

To clarify the swelling and disintegration process of mudstone, specimens influenced by underground stress and water were selected for research. The mudstone was obtained from the Donghuantuo Mine Company in Hebei Province, China (geographic coordinates of $39^{\circ} 38^{\prime} 41.49^{\prime \prime} \mathrm{N}$, $118^{\circ} 0^{\prime} 11.14^{\prime \prime} \mathrm{E}$ ), where the roof of the $-690 \mathrm{~m}$ track roadway comprises mudstone with a thickness of $0.65 \mathrm{~m}$ and the overlying strata of the roof and floor strata are siltstone (Figure 1a). The mudstone of 
the roadway within the mines of this company and of several nearby mines is affected by underground stress and water. During service of the roadway, large deformation of the surrounding rock was discovered. In addition, the central section of the roof is cracked and the boundary between the mudstone and the siltstone is distorted (Figure 1b). In the middle section of the roadway, the top mudstone has collapsed, the overlying siltstone is exposed and seepage can be observed (Figure 1c). Furthermore, the mudstone of the roof expands and undergoes violent disintegration during water soaking processes (Figure 1d).

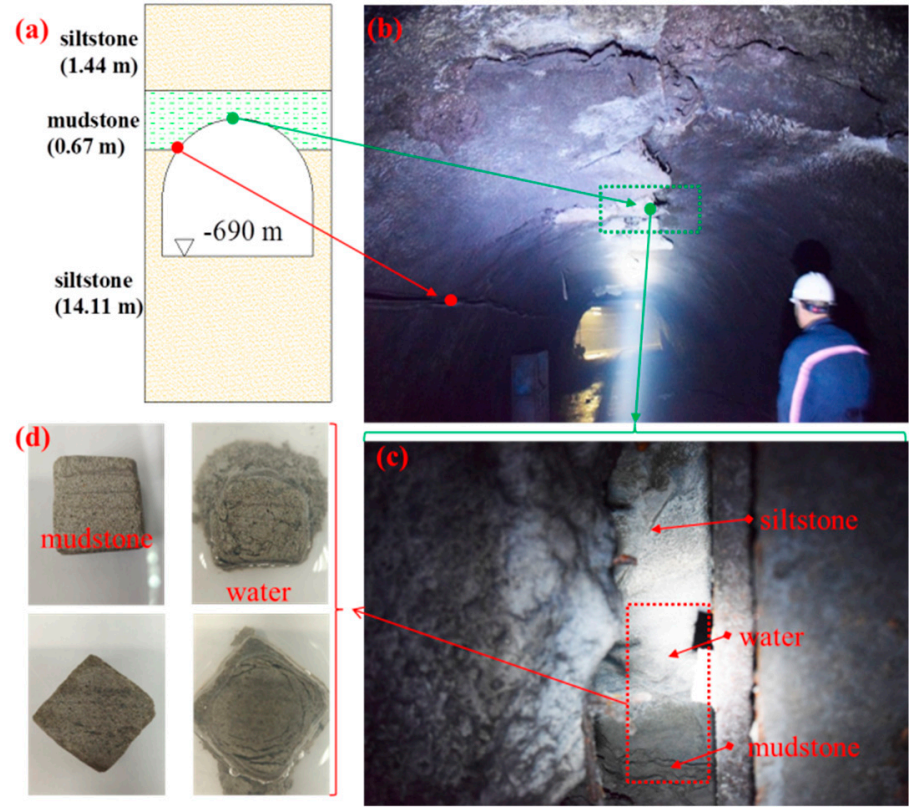

Figure 1. Mudstone disintegration phenomenon. (a) position of roadway, (b) cracked roof and distorted wall, (c) collapsed mudstone and (d) mudstone disintegration.

In similar coal mine engineering, large deformation of the surrounding rock in the water-rich roadway is tightly related to the weakening of mudstone that is reacting with the underground water [23,24]. Under the combined influence of underground water and stress, the mudstone of the roadway roof weakens, the roadway roof undergoes large deformation and the roadway stability is negatively affected.

\subsection{Characterisation}

\subsubsection{X-ray Powder Diffraction (XRD)}

The mineral components of hand-crushed powdered mudstone samples weighing $0.2 \mathrm{~g}$ were quantified using a D/Max-3B X-ray diffractometer. Oriented XRD patterns were collected from $3^{\circ}$ to $70^{\circ}$ (20) at a scanning rate of $2^{\circ} \mathrm{min}^{-1}$ according to the petroleum industry standard (No. SY/T5163-1995). The full-spectrum fitting method (Rietveld method) was used to semi-quantify mineral components [25]; the results are shown in Figure 2. 


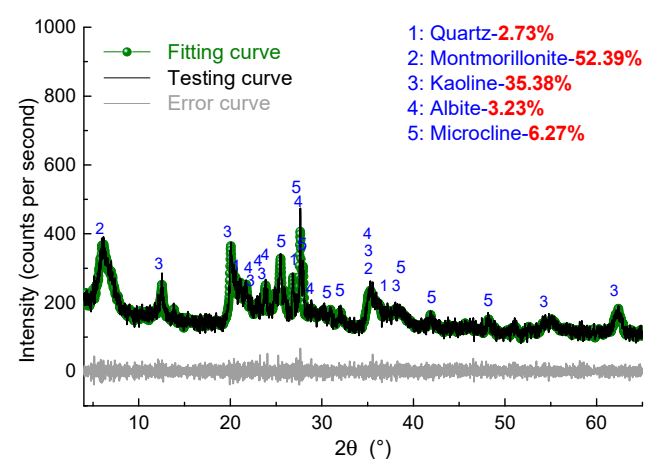

Figure 2. X-ray diffraction and full spectrum analysis.

This mudstone has the tendency to interact with water and disintegrate violently. It contains montmorillonite $(52.39 \%)$, other clay minerals such as kaolin $(35.38 \%)$ and non-clay minerals such as quartz, albite and microcline. The complex mineralogical composition of mudstone makes it difficult to test and fully interpret its disintegration properties. The montmorillonite mineral acts strongly with water and constitutes the matrix of the mudstone, while the kaolinite in the mudstone has a certain degree of water stability [26]; however, the other detrital minerals do not interact with water. As the hydration of montmorillonite aggregate in mudstone largely influences its swelling and disintegration, it is considered that studying the reaction between montmorillonite and water is useful for analysing mudstone properties.

\subsubsection{Field-Emission Scanning Electron Microscopy (FE-SEM)}

FE-SEM images were recorded using an EVOMA 15 scanning electron microscope at an accelerating voltage of $15 \mathrm{kV}$ at working distances (WD) of $13.8 \mathrm{~mm}$ and $13.7 \mathrm{~mm}$, with an amplification factor of $1000 \times$ for both images (Figure 3).
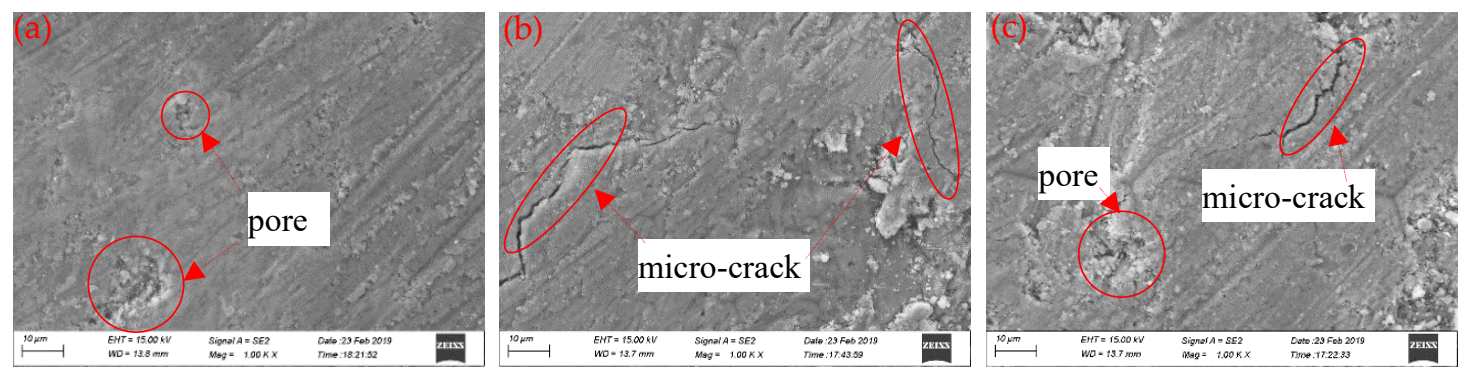

Figure 3. SEM images of sample with (a) pores, (b) micro-cracks and (c) pores and micro-cracks.

Natural mudstone contains micro-pores between the mineral particles and micro cracks created by underground stress. During the process of hydration, water enters the mudstone through these pores and cracks and reacts with the clay minerals, which subsequently affects its mechanical properties.

\subsubsection{Assumptions Used to Describe Mudstone}

On a fine scale, a mudstone sample can be described as a montmorillonite matrix with surrounding inclusions (kaolin, others) (Figure 4) and mudstone is considered to be a matrix-supported rock on this scale [27]. The physical-mechanical properties of the montmorillonite matrix are thus representative of the mudstone. The montmorillonite matrix can also be represented on an even finer scale based on montmorillonite particles and pores. According to the discrete element method (DEM), there are contact forces between adjacent particles [28,29] and pores between the particles influence the mechanical properties of the contact forces. In this respect, mudstone is a naturally occurring multicomponent material composed chiefly of montmorillonite, and the breakage of hydrated mudstone is due to failure of the contact between particles within the montmorillonite matrix. 


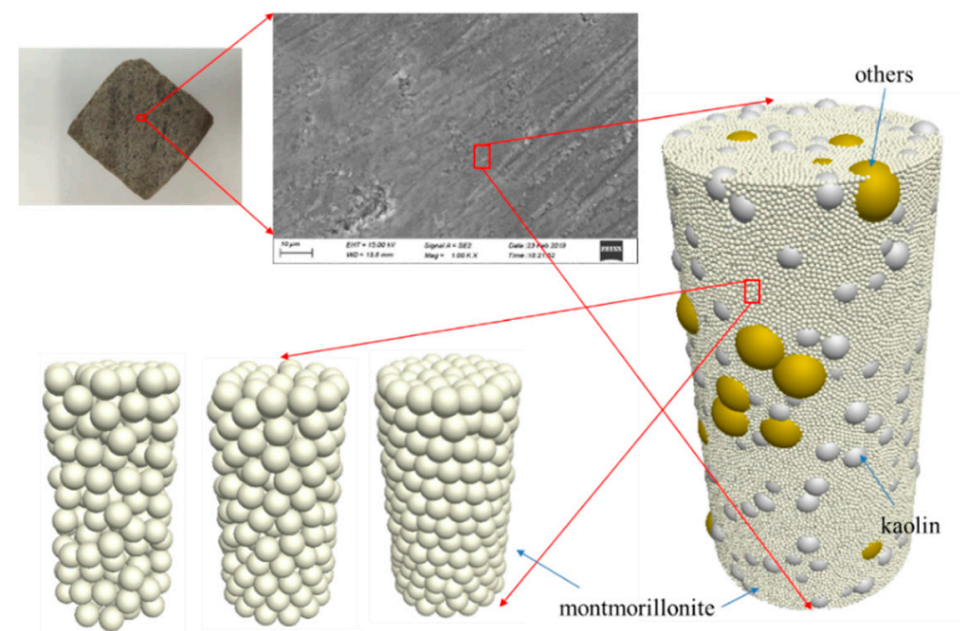

Figure 4. Montmorillonite matrix in mudstone.

\section{Experiments}

The phenomenon of mudstone disintegration mainly occurs due to the swelling and weakening of the montmorillonite mineral component during the process of hydration. Therefore, the main aim of this study was to design an experimental scheme for use in researching the hydration swelling and weakening of the montmorillonite matrix in mudstone. To efficiently investigate the disintegration of mudstone, compacted standard specimens of montmorillonite particles (hereinafter referred to as montmorillonite specimens) were employed as a proxy for the montmorillonite matrix in mudstone.

The montmorillonite particles were dried at $100^{\circ} \mathrm{C}$ for $24 \mathrm{~h}$, mixed with deionised water and then wet with plastic wrap for $24 \mathrm{~h}$ to enable the even absorption of water, as shown in (Figure 5). Compacting the montmorillonite particles with water contents $(w)$ between $15 \%$ and $50 \%$ was found to be straightforward; no obvious water loss occurred during compaction. Therefore, in the experimental scheme, values of $w=15,20,30,40$ and $50 \%$ were employed. This paper presents the investigation of the montmorillonite clay mineral matrix of mudstone excavated from the underground engineering roadway at a depth of $690 \mathrm{~m}$, as the geological depth of China's coal mines is concentrated in the range of approximately -200 to $-1000 \mathrm{~m}$ [30]. The compaction stress (hereinafter referred to as $\sigma_{\text {com }}$ ) was set at values of $5,10,15,20$ and $25 \mathrm{MPa}$.

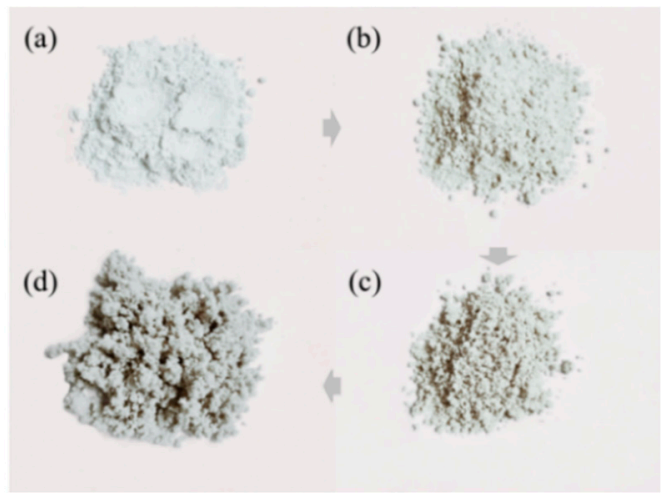

Figure 5. Wet montmorillonite particles with water (w) contents of (a) 15\%, (b) 20\%, (c) 30\% and (d) $40 \%$.

Montmorillonite particle compaction tests were conducted based on the highway geotechnical test standard, No. JTG E40-2007, at an axial strain rate of $2 \%$ the height of the standard uniaxial compression specimen per minute (which is always $2 \mathrm{~mm} / \mathrm{min}$ ). To avoid water loss caused by long-term compaction during the experiment, load holding was held for $10 \mathrm{~min}$ after reaching the required value of $\sigma_{\text {com }}$. Uniaxial compressive tests were conducted on montmorillonite specimens in accordance with the 
rock physical and mechanical properties test standard, No. DZ/T 0276.31-2015, and the displacement rate was set at a constant loading speed of $2 \mathrm{~mm} / \mathrm{min}$. Figure 6 presents the compaction device and sketches of the experimental procedure, which includes loading, load holding, coring and uniaxial compression. It is of note that the analysis of the quality and size of montmorillonite specimens and uniaxial compression tests were conducted immediately after they were cored, in order to minimise the evaporation of water during the experiment.
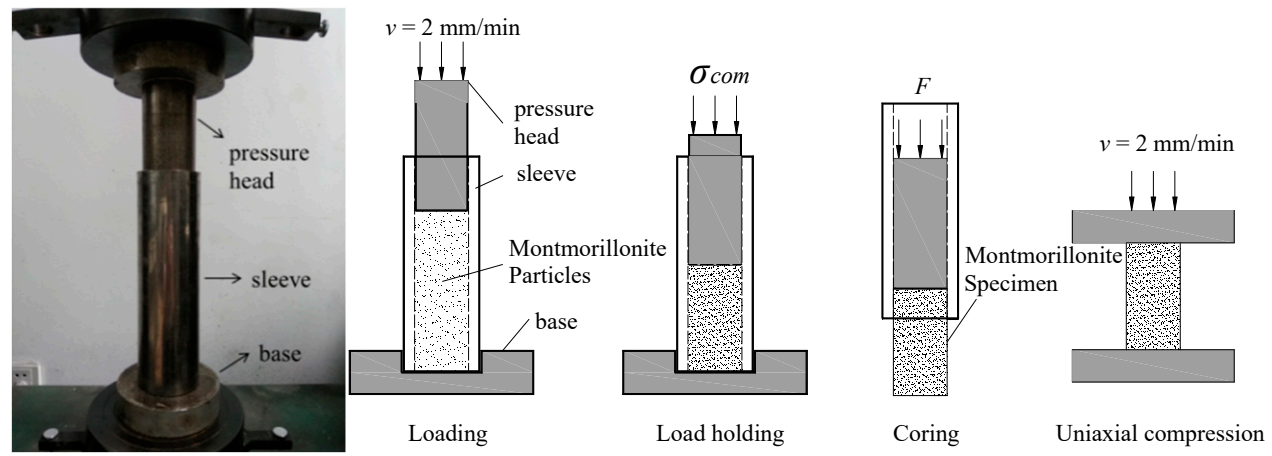

Figure 6. Compaction device and sketches representing the experimental procedure.

\section{Results}

\subsection{Compacted Testing Results}

During the steps of loading and load holding, the stress-displacement curves and the displacement-time curves were plotted; these are shown in Figure 7, where Figure 7a-e shows the experimental results with values of $\sigma_{\text {com }}$ set at 5, 10, 15, 20 and $25 \mathrm{MPa}$, respectively.
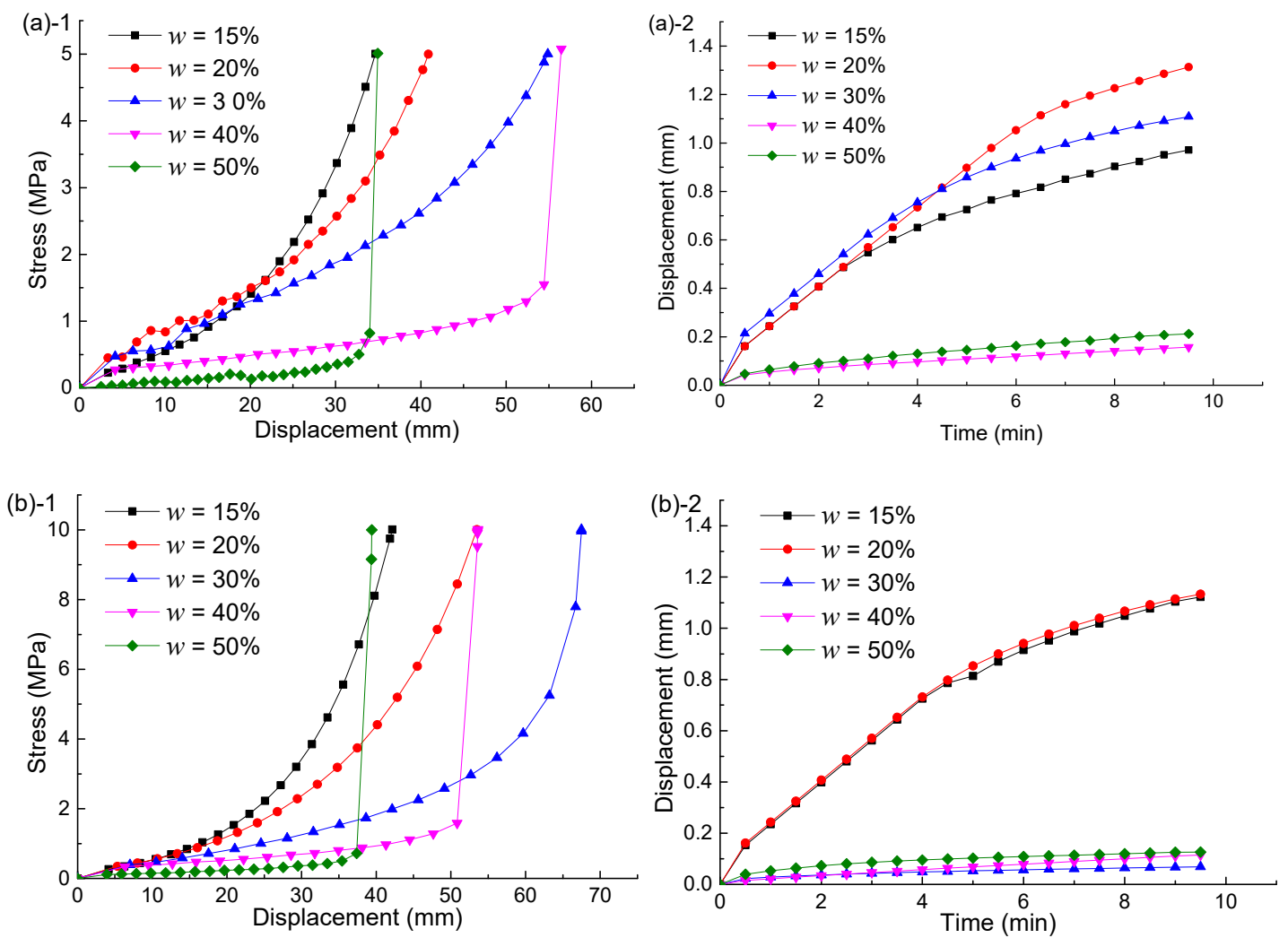

Figure 7. Cont. 

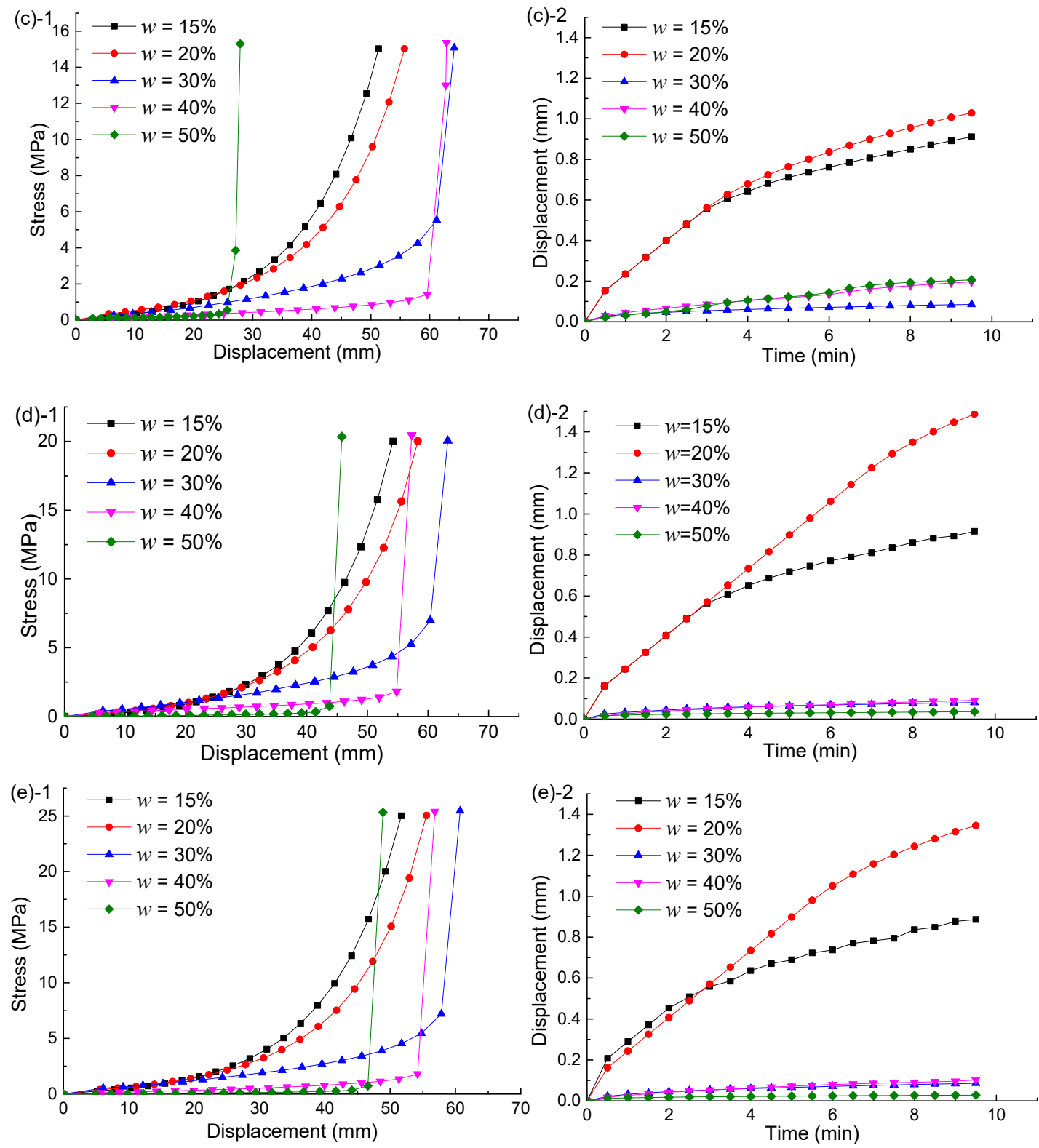

Figure 7. The stress-displacement curves ((a) (e)-1) and the displacement-time curves ((a) (e)-2) under different compaction stresses of (a) $5 \mathrm{MPa}$, (b) $10 \mathrm{MPa}$, (c) $15 \mathrm{MPa}$, (d) $20 \mathrm{MPa}$ and (e) $25 \mathrm{MPa}$.

According to the experimental results shown in Figure 7, when $\sigma_{\mathrm{com}}$ is $5 \mathrm{MPa}$ and $w$ is 40 and $50 \%$, or when $\sigma_{\text {com }}$ is $10,15,20$ and $25 \mathrm{MPa}$ and $w$ is 30,40 and $50 \%$, the stress-displacement curves have a constant slope in the final stage of the loading experimental step and the displacement-time curves have very small displacements $(<0.1 \mathrm{~mm}$ in this experiment). The above experimental phenomena indicate that no violent shift, rotation or compaction occurred between montmorillonite particles during the loading stage and that displacement was mainly related to the elastic deformation of the montmorillonite particles. The aggregate of montmorillonite contains only intergranular micro-voids; thus, not possible for macro-voids to be closed permanently under compression conditions. For a $\sigma_{\text {com }}$ of $25 \mathrm{MPa}$, montmorillonite specimens with a height of approximately $100 \mathrm{~mm}$ and a diameter of $50 \mathrm{~mm}$ are shown in Figure 8. 


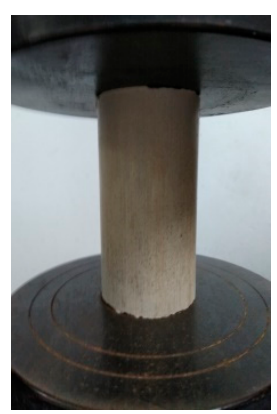

(a)

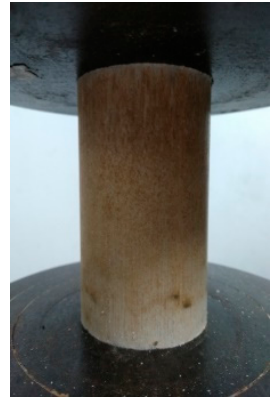

(b)

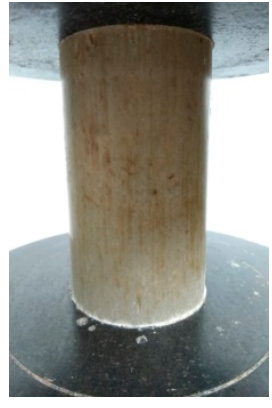

(c)

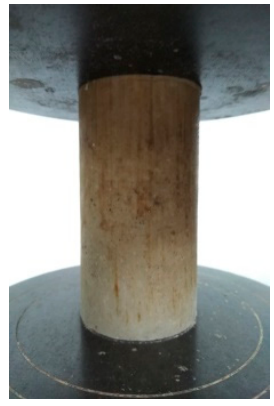

(d)

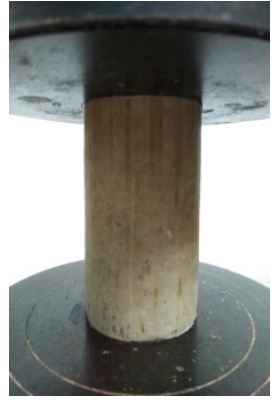

(e)

Figure 8. Montmorillonite specimens with a $w$ of (a) $15 \%$, (b) $20 \%$, (c) $30 \%$, (d) $40 \%$ and (e) $50 \%$ under a $\sigma_{\text {com }}$ of $25 \mathrm{MPa}$.

\subsection{Uniaxial Compression Testing Results}

After the montmorillonite particles were compacted as standard specimens, uniaxial compressive tests were conducted immediately. The stress-strain curves are shown in Figure 9a-e corresponding to $\sigma_{\text {com }}$ values of 5, 10, 15, 20 and $25 \mathrm{MPa}$, respectively.
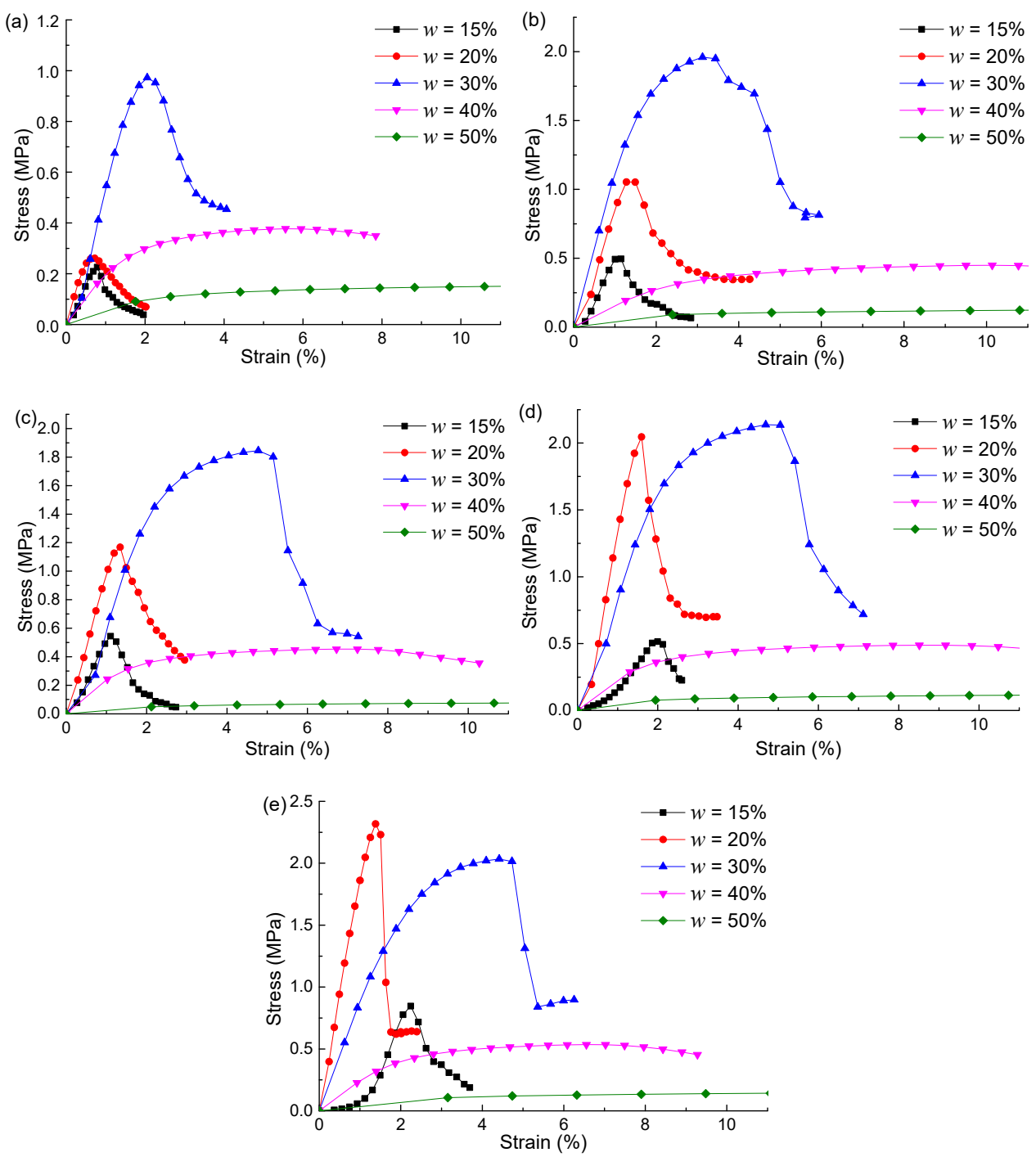

Figure 9. Uniaxial compression tests of montmorillonite specimens under different compaction stresses of (a) $5 \mathrm{MPa}$, (b) $10 \mathrm{MPa}$, (c) $15 \mathrm{MPa}$, (d) $20 \mathrm{MPa}$ and (e) $25 \mathrm{MPa}$. 
The uniaxial compressive strength (hereinafter referred to as UCS) of montmorillonite specimens is related to $\sigma_{\text {com }}$ and $w$. When $\sigma_{\text {com }}$ was $5,10,15$ and $20 \mathrm{MPa}$, the UCS of montmorillonite specimens with $w$ at $30 \%$ was the largest at $0.97,1.97,1.95$ and $2.14 \mathrm{MPa}$, respectively. When $\sigma_{\text {com }}$ was $25 \mathrm{MPa}$, the montmorillonite specimens containing 20\% water had the largest UCS at $2.34 \mathrm{MPa}$. According to the stress-displacement and displacement-time curves plotted in Figure 7, it is evident that when montmorillonite specimens contain less water, they have compressible micro-voids that are supported by the edges of particles. This results in a lower UCS for montmorillonite specimens containing 15\% water as compared to those with water contents of $20 \%$ and $30 \%$. The higher the water content, the lower the UCS of the montmorillonite specimen; therefore, the UCS of montmorillonite specimens with a $w$ of $40 \%$ and $50 \%$ are largely lower than those with a $w$ of $20 \%$ and $30 \%$.

Figure 10 shows the uniaxial compression failure modes of montmorillonite specimens with a $\sigma_{\text {com }}$ of $25 \mathrm{MPa}$, where it is evident that the water content had a significant effect on the uniaxial compression failure mode of the montmorillonite specimens. With an increase in the water content, the fracture mode gradually developed from brittle to ductile fracture and the failure mode developed from tensile failure to shear failure.

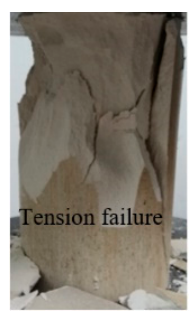

(a)

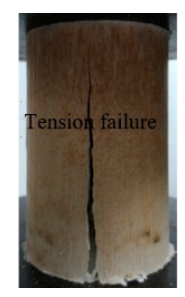

(b)

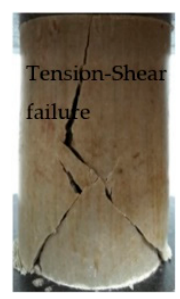

(c)

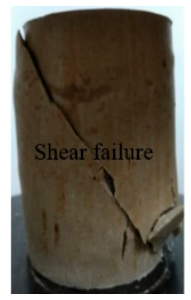

(d)

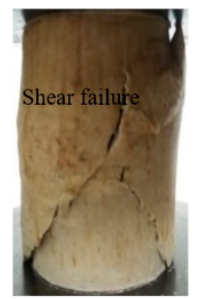

(e)

Figure 10. Uniaxial compression failure modes of montmorillonite specimens with a $w$ of (a) $15 \%$, (b) $20 \%$, (c) $30 \%$, (d) $40 \%$ and (e) $50 \%$ under a $\sigma_{\text {com }}$ of $25 \mathrm{MPa}$.

\section{Discussion}

\subsection{Integrated Specimens}

The dry density of clay is often used to describe the microstructure of compacted specimens because of the complex microstructure with respect to micro-voids [31,32]. In this study, it is difficult to investigate the relationship between mechanical properties and $w$ using the montmorillonite specimens under various compacted stresses, due to the influence of the complex microstructure. Therefore, to conduct such a study, it was necessary to exclude the influence of the microstructure and consider that compacted stress does not affect the physical and mechanical properties of the montmorillonite specimens. Figure 11 shows the densities (Figure 11a) and UCSs (Figure 11b) of montmorillonite specimens plotted in the plane of compacted stress, $\sigma_{\text {com }}$.

When $w$ was $15 \%$ and $20 \%$, the density and uniaxial compression strength increased with an increase in the compacted stress; however, they did not change with an increase in compacted stress for montmorillonite specimens with a $w$ of $40 \%$ and $50 \%$ (hereinafter referred to as the integrated specimens). The montmorillonite with a $w$ of $20 \%$ was found to have two properties: density and uniaxial compression strength increased during the first low-stress stage but in the later high-stress stage they were stable.

The experimental data show that the density and uniaxial compression strength of montmorillonite specimens with a higher water content $(w>40 \%)$ are independent of compacted stress. This shows that montmorillonite specimens undergo elastic deformation with an increase in compacted stress, while when the compacted stress is withdrawn, the elastic deformation is reversible. Hereinafter, these specimens are referred to as integrated specimens. 

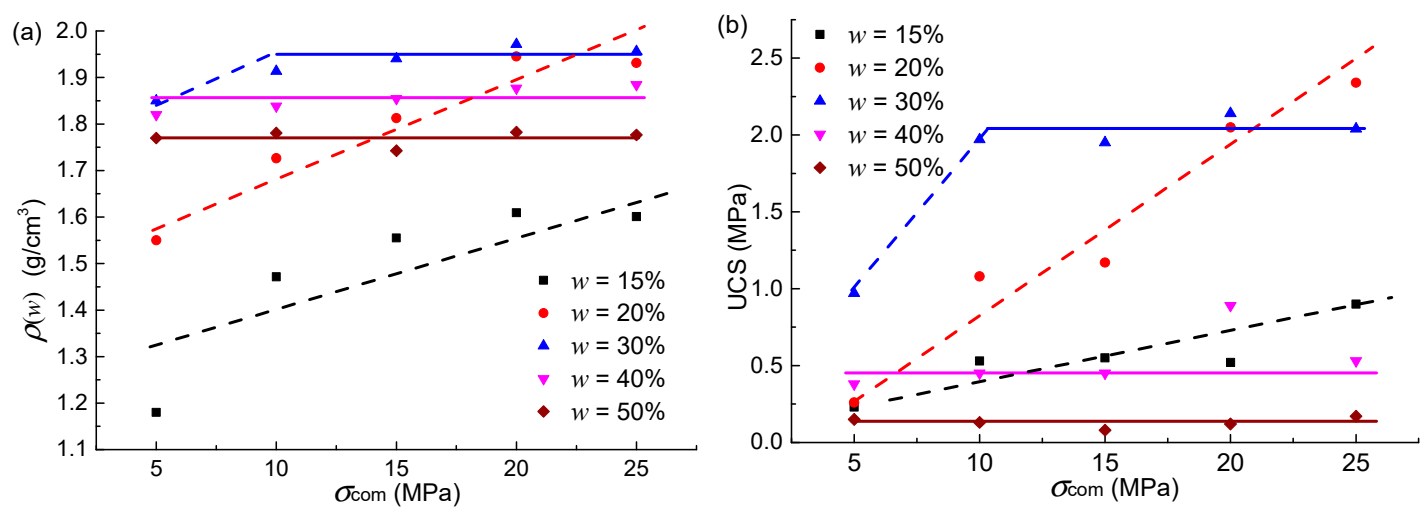

Figure 11. Relationship between (a) densities and (b) uniaxial compressive strengths (UCSs) of montmorillonite specimens and $\sigma_{\text {com }}$.

\subsection{Hydration Swelling Model}

Montmorillonite hydration causes an increase in the distance between the montmorillonite layers, as the water intrudes into spaces between the layers [33,34]. Montmorillonite particles are formed by the stacking of numerous parallel crystal layers [35], which swell in response to an increase in water molecules. This causes adsorption energy within the montmorillonite layers and interlayer cations are activated within crystal layer spaces [36]. The swelling of particles is a non-negligible factor, because it increases their considerable ability to absorb water within the interlayer spaces. The expansion of the crystal layers of montmorillonite particles occurs in two stages: crystalline swelling and osmotic swelling [37]. Crystalline swelling refers to the surface hydration of the crystal layer and the hydration expansion of interlayer ions; osmotic swelling refers to osmotic expansion caused by the difference in the ion concentration between the inner and outer crystal layers. There may be one, two or three water molecule layers between layers within a montmorillonite particle and the corresponding layer spacing is 12.2-12.8 $\AA, 15.0-15.6 \AA$ and $18.1-18.7 \AA$, respectively [34]. These montmorillonite layer distances are equal to $10,12.6,15.6,18.6$ or $21.6 \AA$, which correspond to $0,1,2,3$ or 4 water layers [38]. These distances increase linearly with an increase in the number of water layers between the layers.

The increased volume of water within the space between montmorillonite layers decreases the density of montmorillonite particles. Experimental data for the densities of montmorillonite specimens with respect to water content $(w)$ are plotted in Figure 12, and data are available for $w$ values of 15, 20, 30,40 and $50 \%$. These data are seen to form a linear relationship with respect to the density versus water content $(w)$ space for integrated specimens, although it is evident that the datapoints themselves are relatively scattered.

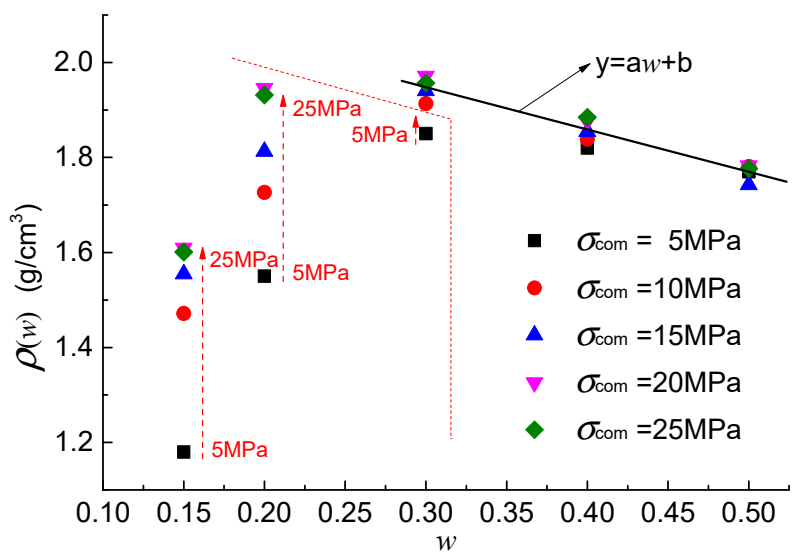

Figure 12. Relationship between montmorillonite specimen density and $w$. 
A linear relation can be used to express the relationship between density and $w$ as follows:

$$
\rho(w)=a w+b
$$

where $\rho(w)$ is the density of an integrated specimen with different water contents, $\mathrm{g} / \mathrm{cm}^{3} ; w$ is the water content; $a, b$ are constants.

To eliminate errors relating to conducting a single experiment and to verify the rationality of the linear relationship shown in Equation (1), compaction tests with a compacted stress of $25 \mathrm{MPa}$ and uniaxial compressive tests were again conducted in accordance with the above experimental scheme. Data for water contents of 30, 35, 42 and $47 \%$ are presented in Table 1

Table 1. Density and UCS of integrated montmorillonite specimens.

\begin{tabular}{cccccccc}
\hline$w$ & $\begin{array}{c}\sigma_{\text {com }} \\
(\mathbf{M P a})\end{array}$ & \multicolumn{2}{c}{$\begin{array}{c}\rho \\
\left(\mathrm{g} / \mathbf{c m}^{3}\right)\end{array}$} & $\begin{array}{c}\bar{\rho} \\
\left(\mathrm{g} / \mathbf{c m}^{3}\right)\end{array}$ & \multicolumn{2}{c}{$\begin{array}{c}\text { UCS } \\
\mathbf{M P a}\end{array}$} & $\begin{array}{c}\text { UCS } \\
\mathbf{M P a}\end{array}$ \\
\hline 0.3 & 25 & 1.95 & 1.96 & 1.955 & 1.85 & 1.92 & 1.885 \\
0.35 & 25 & 1.88 & 1.87 & 1.875 & 0.78 & 0.76 & 0.77 \\
0.42 & 25 & 1.83 & 1.83 & 1.83 & 0.46 & 0.37 & 0.415 \\
0.47 & 25 & 1.75 & 1.76 & 1.755 & 0.23 & 0.23 & 0.23 \\
\hline
\end{tabular}

The relationship between the average density and $w$ was linearly fitted and is shown in Figure 13. It is considered that the fitting equation (Equation (2)) accurately describes the hydration swelling of integrated specimens with a goodness of fit of 0.96 , and this accurately reflects the hydration swelling properties of integrated specimens:

$$
\rho(w)=2.28-1.10 w
$$

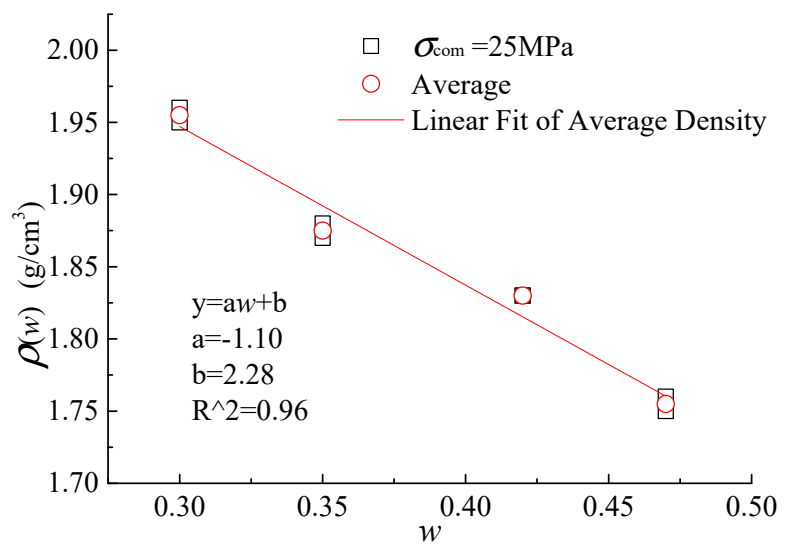

Figure 13. Linear fit for relationship between density and water content.

All the densities of integrated specimens obtained earlier were plotted within the space of density versus water content (Figure 14) and compared with data calculated by Equation (2). The experimental results were found to be in good agreement with the calculated results for the hydration swelling model obtained above; therefore, its rationality was verified. This model reflects the swelling properties of montmorillonite specimens and the decrease in density during water absorption. Therefore, the water swelling law of the integrated montmorillonite matrix in mudstone can be indirectly characterised by determining the water content within it. 


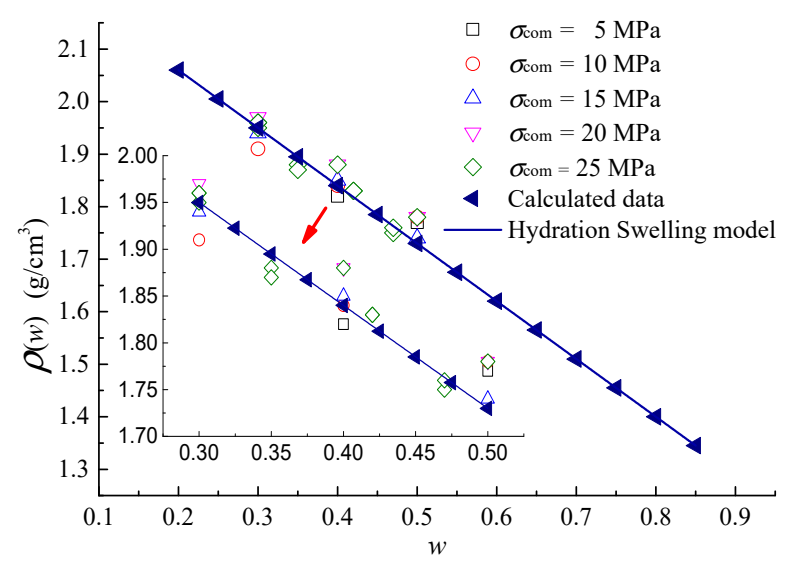

Figure 14. Hydration swelling model of integrated specimens.

\subsection{Hydration Weakening Model}

According to the hydration swelling model, water molecules entering the spaces of montmorillonite layers during the process of hydration increase the spaces of the layers and then expand the montmorillonite particles. The unbalanced gravitational and repulsive force between the montmorillonite layers leads to a change in the interlayer spaces. The repulsive force includes the cationic hydration force, the electrostatic force between the layers and osmotic pressure; and the gravitational force includes van der Waals force and the force between interlayer cations and the crystal layer surface. For fine montmorillonite particles, the particle cement force is the sum of the electronic force and van der Waals force (among other components that can be neglected in the present analyses). The van der Waals force is inversely proportional to the fourth power of the distance, and the electrostatic interaction between the charges on the surface of particles is inversely proportional to the square of the distance [39]. Therefore, the force between montmorillonite particles can be simplified into Equation (3) as follows:

$$
F=a_{1} D^{-4}+b_{1} D^{-2}
$$

where $F$ is the force between montmorillonite particles; $D$ is distance between montmorillonite particles; $a_{1}$ and $b_{1}$ are constants.

This study assumes that montmorillonite particles are basic elements that can be used to study swelling properties. The discrete element method shows that specimens are composed of particles connected by cements. With the hydration of montmorillonite particles, the particle volume increases and the distance between montmorillonite particles increases due to the increased layer space (filling with water). A model of the weakening of montmorillonite particles with respect to hydration is schematically shown in (Figure 15).

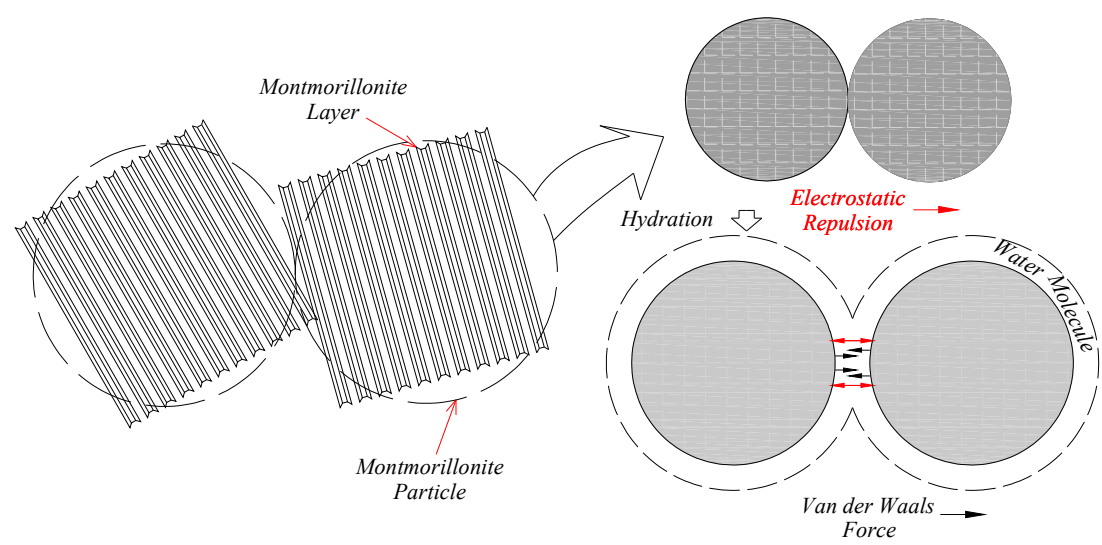

Figure 15. Hydration of montmorillonite particles. 
During the process of water absorption by montmorillonite, the increased distance between the particles occurs with respect to the increase in the interlayer of water molecules at mutual contact positions. The interlayer distance between particles increases linearly with the increase of water; therefore, when one layer of water molecules is added, the interlayer space is increased by $2.8 \sim 3.1$ $\AA[1,34,38]$. Thus, the distance between montmorillonite particles increases linearly with an increase in water and the force between particles can be expressed by the water content as shown in Equation (4):

$$
F=a_{2} w^{-4}+b_{2} w^{-2}
$$

The mass $m(w)$ of fully compacted montmorillonite aggregates containing water can be calculated by Equation (5), where $m_{0}$ is the dry mass of the integrated specimen:

$$
m(w)=(1+w) m_{0}
$$

After hydration swelling, the volume $V(w)$ of an integrated specimen can be calculated by its dry volume $V_{0}$ and $w$, where it is assumed that function $f(w)$ satisfies Equation (6).

$$
V(w)=V_{0} \cdot f(w)
$$

According to the above hydration swelling model, the density of an integrated specimen decreases linearly with an increase in $w$. Its density $\rho(w)$ can be calculated by Equation (7), and finally the function $f(w)$ can be expressed by Equation (8):

$$
\begin{gathered}
\rho(w)=\frac{m(w)}{V(w)}=\frac{(1+w) m_{0}}{V_{0} \cdot f(w)}=\frac{(1+w)}{f(w)} \rho_{0}, \\
f(w)=\frac{(1+w)}{k w+c},
\end{gathered}
$$

where $\rho_{0}$ is the density of a dry integrated specimen and $k$ and $c$ are constants.

An integrated specimen consists of numerous montmorillonite particles. According to Equation (6), the radius of a montmorillonite particle $R(w)$ can be calculated by Equation (9), where $R_{0}$ is the diameter of the dry montmorillonite particle:

$$
R(w)=R_{0} \cdot \sqrt[3]{\frac{1+w}{k w+c}}
$$

According to the discrete element method, the cement between particles is circular with a particular radius $(r)$. Therefore, the strength of cement $[\sigma]$ can be expressed by Equation (10):

$$
[\sigma]=\frac{F}{\pi r^{2}}=\frac{a_{2} w^{-4}+b_{2} w^{-2}}{\pi r^{2}}
$$

During the process of conducting uniaxial compressive tests on integrated specimens, the cement between the montmorillonite particles breaks when the compressive stress surpasses the strength of the cement. The maximal compressive stress $\sigma_{c \max }$ is shown in Equation (11):

$$
\sigma\left(\frac{r}{R(w)}\right)^{2} \text { ccmax }
$$

The radius of a dry montmorillonite particle is a constant and the maximal compressive stress can be simplified into Equation (12), where $A$ and $B$ are constants:

$$
\sigma\left(A w^{-4}+B w^{-2}\right)\left(\frac{1+w}{k w+c}\right)^{2 / 3} c \max
$$


To determine the constants in Equation (12), a fitting equation for the experimental results shown in Table 1 was obtain based on Equation (12), with $w$ in the range of 0-0.87. A goodness of fit degree of 0.99 was obtained, as shown in Equation (13):

$$
\mathrm{UCS}=\left(0.018 w^{-4}-0.014 w^{-2}\right) /\left(\frac{1+w}{1.960-2.249 w}\right)^{2 / 3}
$$

In Figure 16, the UCS results of all the integrated specimens obtained earlier are plotted in the space of UCS versus water content and are compared with the data calculated by Equation (13). As the experimental results are in good agreement with the calculation results, the rationality of this method can thus be verified. This model reflects the hydration weakening properties of montmorillonite aggregates, as there is a decrease in UCS during water absorption. Moreiver, the hydration weakening law of integrated montmorillonite matrix in mudstone can be indirectly determined when the water content of mudstone is known.

With a low water content $(w<0.2$ in this paper), the UCS of the integrated specimen exceeded $12 \mathrm{MPa}$. With an increase in the water content, the UCS firstly decreased sharply and then gradually stabilised at zero. With a $w$ of 0.6 , the UCS was $0.04 \mathrm{MPa}$ and the montmorillonite aggregates can flow and provided no bearing capacity at all under the experimental conditions.

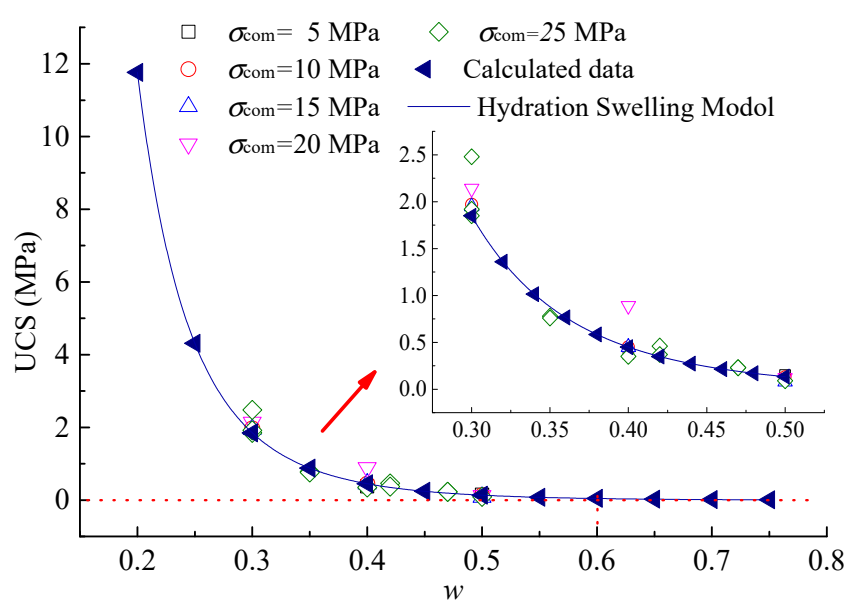

Figure 16. Model of hydration weakening of integrated specimens.

\section{Conclusions}

An experimental scheme consisting of compaction tests and uniaxial compressive tests was designed in this study to investigate the hydration swelling and weakening of the montmorillonite matrix in mudstone. The following conclusions can be made:

(1) This broken mudstone contains montmorillonite (52.39\%), other clay minerals such as kaolin $(35.38 \%)$ and non-clay minerals such as quartz, albite and microcline. The swelling and disintegration of mudstone is a naturally occurring phenomenon within the multicomponent material that is composed mainly of montmorillonite. The breakage of this hydrated mudstone is closely related to failure of the montmorillonite matrix and is influenced by the presence of micro-pores and -cracks.

(2) The results of compacted tests and uniaxial compression tests show that an integrated specimen is a compacted standard specimen that has no change in its density or UCS with an increase in compacted stress. Such specimens can be used to represent the integrated montmorillonite matrix in mudstone as well as to study the swelling and disintegration properties of the montmorillonite matrix in this kind of mudstone, which is mainly composed of montmorillonite.

(3) According to the hydration swelling model of montmorillonite, the density of the integrated montmorillonite matrix declines linearly with an increase in the water content, which can be explained by the linear increase of distance between montmorillonite layers. Therefore, the montmorillonite 
matrix of mudstone expands linearly in response to an increase in the water content. The expansion of montmorillonite induced the swelling and disintegration of this kind of mudstone.

(4) According to the hydration weakening model of montmorillonite, which is a combination of electrostatic force and van der Waals force and is based on the discrete element method, the uniaxial compressive strength of an integrated specimen first decreases sharply and then gradually stabilises at zero with an increase in $w$. Under experimental conditions, the UCS was only $0.04 \mathrm{MPa}$ with a $w$ of 0.6 ; montmorillonite particles with $w$ of 0.6 exhibit fluidity, which causes the mudstone to disintegrate.

It is of note that the above hydration weakening model is based on the assumption that the particles are spherical. The actual structure of compacted clay is, however, more complex; therefore, the applicability of this model will be further investigated in future studies.

Author Contributions: C.S., G.L. conceived and designed the experiments; C.S., Y.S. and J.H. performed the experiments and analyzed the data; C.S., Y.S. and H.R. wrote the paper.

Funding: This work was supported by the National Key Research and Development Program (2016YFC0600901), National Natural Science Foundation of China (No. 51574224) and Priority Academic Program Development of Jiangsu Higher Education Institutions (PAPD).

Acknowledgments: The authors are very grateful to the authors of all the references and the anonymous reviewers for carefully reading the manuscript and providing many helpful comments. Finally, Changlun Sun wants to thank, in particular, the powerful support received from his girlfriend Fan Zhou over the years.

Conflicts of Interest: The authors declare no conflict of interest.

\section{References}

1. Li, G.C.; Jiang, Z.H.; Feng, X.W.; Zhang, N.; Xu, X.L. Relation between molecular structure of montmorillonite and liquefaction of mudstone. RSC Adv. 2015, 5, 23481-23488. [CrossRef]

2. Tetsuka, H.; Katayama, I.; Sakuma, H.; Kenji, T. Effects of humidity and interlayer cations on the frictional strength of montmorillonite. Earth Planets Space 2018, 70, 56. [CrossRef]

3. Li, H.L.; Zhao, Y.L.; Song, S.X.; Hu, Y.; Nahmad, Y. Delamination of Na-montmorillonite particles in aqueous solutions and isopropanol under shear forces. J. Disper. Sci. Technol. 2017, 38, 1117-1123. [CrossRef]

4. Zhou, C.Y.; Deng, Y.M.; Tan, X.S.; Liu, Z.Q.; Shang, W.; Zhan, S. Experimental research on the softening of mechanical properties of saturated soft rocks and application. Chin. J. Rock Mech. Eng. 2005, 24, 33-38.

5. Ghorbani, A.; Zamora, M.; Cosenza, P. Effects of desiccation on the elastic wave velocities of clay-rocks. Int. J. Rock Mech. Min. Sci. 2009, 46, 1267-1272. [CrossRef]

6. Yang, D.S.; Billiotte, J.; Su, K. Characterization of the hydromechanical behavior of argillaceous rocks with effective gas Permeability under deviatoric stress. Eng. Geol. 2010, 114, 116-122. [CrossRef]

7. Yang, D.S.; Bornert, M.; Chanchole, S.; Wang, L.L.; Valli, P. Experimental investigation of the delayed behavior of unsaturated argillaceous rocks by means of digital image correlation techniques. Appl. Clay Sci. 2011, 54, 53-62. [CrossRef]

8. Zhang, F.; Xie, S.Y.; Hu, D.W.; Shao, J.F.; Gatmiri, B. Effect of water content and structural anisotropy on mechanical property of claystone. Appl. Clay Sci. 2012, 69, 79-86. [CrossRef]

9. Guéry, A.; Cormery, F.; Shao, J.F.; Kondo, D. A micromechanical model of elastoplastic and damage behavior of a cohesive geomaterial. Int. J. Solids Struct. 2008, 45, 1406-1429. [CrossRef]

10. Robinet, J.C.; Sardini, P.; Coelho, D.; Parneix, J.C.; Prêt, D.; Sammartino, S.; Boller, E.; Altmann, S. Effects of mineral distribution at mesoscopic scale on solute diffusion in a clay-rich rock: Example of the Callovo-Oxfordian mudstone (Bure, France). Water Resour. Res. 2012, 48, W05554. [CrossRef]

11. Armand, G.; Conil, N.; Talandier, J.; Seyedi, D. Fundamental aspects of the hydromechanical behaviour of Callovo-Oxfordian claystone: From experimental studies to model calibration and validation. Comput. Geotech. 2017, 85, 277-286. [CrossRef]

12. Oohashi, K.; Hirose, T.; Takahashi, M.; Tanikawa, W. Dynamic weakening of smectite-bearing faults at intermediate velocities: Implications for subduction zone earthquakes. J. Geophys. Res. Solid Earth 2015, 120, 1572-1586. [CrossRef]

13. Takahashi, M.; Mizoguchi, K.; Kitamura, K.; Masuda, K. Effects of clay content on the frictional strength and fluid transport property of faults. J. Geophys. Res. Solid Earth 2007, 112, B8. [CrossRef] 
14. Tembe, S.; Lockner, D.A.; Wong, T. Effect of clay content and mineralogy on frictional sliding behavior of simulated gouges: Binary and ternary mixtures of quartz, illite, and montmorillonite. J. Geophys. Res. Solid Earth 2010, 115, B3. [CrossRef]

15. Matsumoto, S.; Shimada, H.; Sasaoka, T. Interaction between physical and chemical weathering of argillaceous rocks and the effects on the occurrence of acid mine drainage (AMD). Geosci. J. 2017, 21, 1-10. [CrossRef]

16. He, M.C.; Zhou, L.; Li, D.J.; Wang, C.G.; Nie, W. Experimental research on hydrophilic characteristics of mudstone in deep well. Chin. J. Rock Mech. Eng. 2008, 27, 1113-1120.

17. Chai, Z.Y.; Zhang, Y.T.; Zhang, X.Y. Experimental investigations on correlation with slake durability and mineral composition of mudstone. J. China Coal Soc. 2015, 40, 1188-1193.

18. Mukherjee, K.; Mishra, A.K. Hydraulic and mechanical characteristics of compacted sand-bentonite: Tyre chips mix for its landfill application. Environ. Dev. Sustain. 2019, 21, 1411-1428. [CrossRef]

19. Villar, M.V.; Antonio, L. Influence of dry density and water content on the swelling of a compacted bentonite. Appl. Clay Sci. 2009, 39, 38-49. [CrossRef]

20. Xu, S.F.; Li, G.F.; Liu, J.Z.; Bian, M.D.; Wei, W.W.; Zhang, H.; Wang, Z. Deformation and hydraulic conductivity of compacted clay under waste differential settlement. Processes 2018, 6, 123. [CrossRef]

21. Nilo, C.C.; Eduardo, J.B.M.; Rubén, A.Q.S.; Hugo, C.S.F.; Carlos, S.F.; Tiago, M.; Nuno, C. Effect of mellowing and coal fly ash addition on behavior of sulfate-rich dispersive clay after lime stabilization. J. Mater. Civ. Eng. 2019, 31, 04019071.

22. Kumar, A.; Walia, B.S.; Mohan, J. Compressive strength of fiber reinforced highly compressible clay. Constr. Build. Mater. 2006, 20, 1063-1068. [CrossRef]

23. Xu, X.L.; Zhang, N. Study of control process deformation behavior and of soft rock drift under rich condition. J. China Univ. Min. Technol. 2007, 36, 298-302.

24. Li, S.Q.; Feng, T.; Wang, G.L.; Pan, C.L. Study on mechanism and control of soft rock roadway floor heave in Gequan Goal Ming. Chin. J. Rock Mech. Eng. 2005, 24, 1450-1455.

25. Ruan, C.D.; Ward, C.R. Quantitative X-ray powder diffraction analysis of clay minerals in Australian coals using Rietveld methods. Appl. Clay Sci. 2002, 21, 227-240. [CrossRef]

26. Mckissock, I.; Walker, E.L.; Gilkes, R.J.; Carter, D.J. The influence of clay type on reduction of water repellency by applied clays: A review of some West Australian work. J. Hydrol. 2000, 231, 323-332. [CrossRef]

27. Cariou, S.; Dormieux, L.; Skoczylas, F. An original constitutive law for Callovo-Oxfordian argillite, a two-scale double-porosity material. Appl. Clay Sci. 2013, 80, 18-30. [CrossRef]

28. Vesga, L.F.; Vallejo, L.E.; Lobo-Guerrero, S. DEM analysis of the crack propagation in brittle clays under uniaxial compression tests. Int. J. Numer. Anal. Met. 2008, 32, 1405-1415. [CrossRef]

29. Bayesteh, H.; Mirghasemi, A.A. Numerical simulation of pore fluid characteristic effect on the volume change behavior of montmorillonite clays. Comput. Geotech. 2013, 48, 146-155. [CrossRef]

30. He, M.C.; Xie, H.P.; Peng, S.P.; Jiang, Y.D. Study on rock mechanics in deep mining engineering. Chin. J. Rock Mech. Eng. 2005, 24, 2803-2813.

31. Pintado, X.; Romero, E.; Suriol, A.; Lloret, A.; Madhusudhan, B.N. Small-stain shear stiffness of compacted bentonites for engineered barrier system. Geomech. Eng. Geol. Environ. 2019, 8, 1-12.

32. Mašín, D.; Khalili, N. Swelling phenomena and effective stress in compacted expansive clays. Can. Geotech. J. 2016, 53, 134-147. [CrossRef]

33. Zheng, Y.; Zaoui, A. How water and counterions diffuse into the hydrated montmorillonite. Solid State Ionics 2011, 203, 80-85. [CrossRef]

34. Oueslati, W.; Rhaiem, H.B.; Amara, A.B.H. XRD investigations of hydrated homoionic montmorillonite saturated by several heavy metal cations. Desalination 2011, 271, 139-149. [CrossRef]

35. Brice, F.; Ngouana, W.; Kalinichev, A.G. Structural arrangements of isomorphic substitutions in smectites: Molecular simulation of the swelling properties, interlayer structure, and dynamics of hydrated Cs-montmorillonite revisited with new clay models. J. Phys. Chem. C 2014, 118, 12758-12773.

36. Salles, F.; Douillard, J.M.; Bildstein, O.; Gaudin, C.; Prelot, B.; Zajac, J.; Damme, H.V. Driving force for the hydration of the swelling clays: Case of montmorillonites saturated with alkaline-earth cations. J. Coll. Interface Sci. 2013, 395, 269-276. [CrossRef]

37. Greathouse, J.A.; Cygan, R.T.; Fredrich, J.T.; Jerauld, G.R. Molecular dynamics simulation of diffusion and electrical conductivity in montmorillonite interlayers. J. Phys. Chem. C 2016, 120, 1640-1649. [CrossRef] 
38. Saiyouri, N.; Hicher, P.Y.; Tessier, D. Microstructural approach and transfer water modelling in highly compacted unsaturated swelling clays. Mech. Cohes-Fric Mater. 2000, 5, 41-60. [CrossRef]

39. Li, G.X.; Zhang, B.Y.; Yu, Y.Z. Soil Mechanics; Tsinghua University Press: Beijing, China, 2013; pp. 28-31.

(c)

(C) 2019 by the authors. Licensee MDPI, Basel, Switzerland. This article is an open access article distributed under the terms and conditions of the Creative Commons Attribution (CC BY) license (http://creativecommons.org/licenses/by/4.0/). 